\title{
From the Digital to the Discrete
}

\section{MOLLIE CLAYPOOL}

The Bartlett, University College London
This paper, will acknowledge that the discipline of architecture, which was foregrounding and highly influential in its adoption of digital tools in the late 1980s and early 1990s, has to now rethink entirely what 'becoming digital' has meant for architecture in order for it to continue to be a social and cultural pursuit, able to provoke and enable real change for those who we are meant to serve. What are the social, economic and political consequences of the digital for the production of architecture? And how can cultural changes - in the structure of our communities (familial or otherwise) and in the way that we relate to our virtual and physical environments - be responded to by architecture in a way which empowers and enables these communities to be active co-producers of their virtual and physical environments? The paper will critique previous generations of 'digital' designers, speculating on how an all-digital discrete approach to architecture could enable architecture to be able to provide possible answers to the above questions. It will present aspects of a theoretical framework that promotes a possible answer to the consequences 'becoming digital' has had in the architectural discipline through the concept of the 'all-digital' and the 'discrete'. It will refer to work in philosophy and cultural theory that speculates on full automation as happening in the near-now and align itself with the work of left-accelerationists such as Nick Scrnicek, Alex Williams, Benjamin Bratton and the Xenofeminist collective Laboria Cuboniks. Towards the end of the paper possible potential avenues for development of the 'discrete' will be briefly demonstrated through projects developed over the last several years with students from the Unit 19 in Design Computation Lab, which is directed by Mollie Claypool, Manuel Jimenez Garcia, Gilles Retsin and Vicente Soler at The Bartlett School of Architecture, UCL. Abstract Here.

If General Motors had kept up with the technology like the computer industry has, we would all be driving $\$ 25.00$ cars that got 1,000 miles to the gallon.

$$
\text { -Bill Gates }{ }^{1}
$$

The digitisation of our contemporary world is ubiquitous, enabling even the farthest reaches of our planet to be connected with relative ease; from Antartica to the North Pole. This is argued as a cultural shift, one which when we look to architecture can be considered complete, or as this session 'Becoming Digital' wishes to argue, in a continuous state of becoming even more digital. Yet over twenty years on, this famous quote used by Microsoft CEO Bill Gates to emphasise transformations within the technology and communication sectors would be even more antithetical still if applied today to the production of the built environment. While both electronic devices and cars have dramatically increased in quality and efficiency in terms of their use of the digital, a typical building is not made in a factory, but by people in the field. As our homes, civic and cultural spaces and workspaces are being invaded by 'smart' gadgets and the Internet of Things, their basic building blocks are typically planned and put together through processes that have not changed much within the last century. Powerful and not-so-subtle political and economic structures maintain this as the status quo in the production of architecture and the built environment, relegating contemporary architecture to the domain of the surface: the design of the facade, the interior wall or the suspended ceiling.

This paper is concerned with this discrepancy between the ways that we live/work, and the ways that we design in digital environments and produce architecture in the physical world. Concerned with the manufacturing ecologies and value systems that contribute to this dichotomy, the paper will oscillate in the boundaries between academic, experimental or speculative practice and professional architectural production, arguing that doing so is an important political position to take today. Refuting the role of the architect in the production of buildings, which appears to have been reduced to that of an aestheticist at the service of neo-liberal modes of project development, the paper will acknowledge that the discipline of architecture, which was foregrounding and highly influential in its adoption of digital tools in the late 1980s and early 1990s, has to now rethink entirely what 'becoming digital' has meant for architecture in order for it to continue to be a social and cultural enterprise, able to provoke and enable real change for those who we are meant to serve (hence the politics). The position taken will emphasise that there are important connections between how we think about design, do design and construct the built environment, and the ways in which we live and the quality of life that we have.

What are the social, economic and political consequences of the digital for the production of architecture? And how can cultural changes - in the structure of our communities (familial or otherwise) and in the way that we relate to our virtual and physical environments - be responded to by architecture in a way which empowers and enables these 


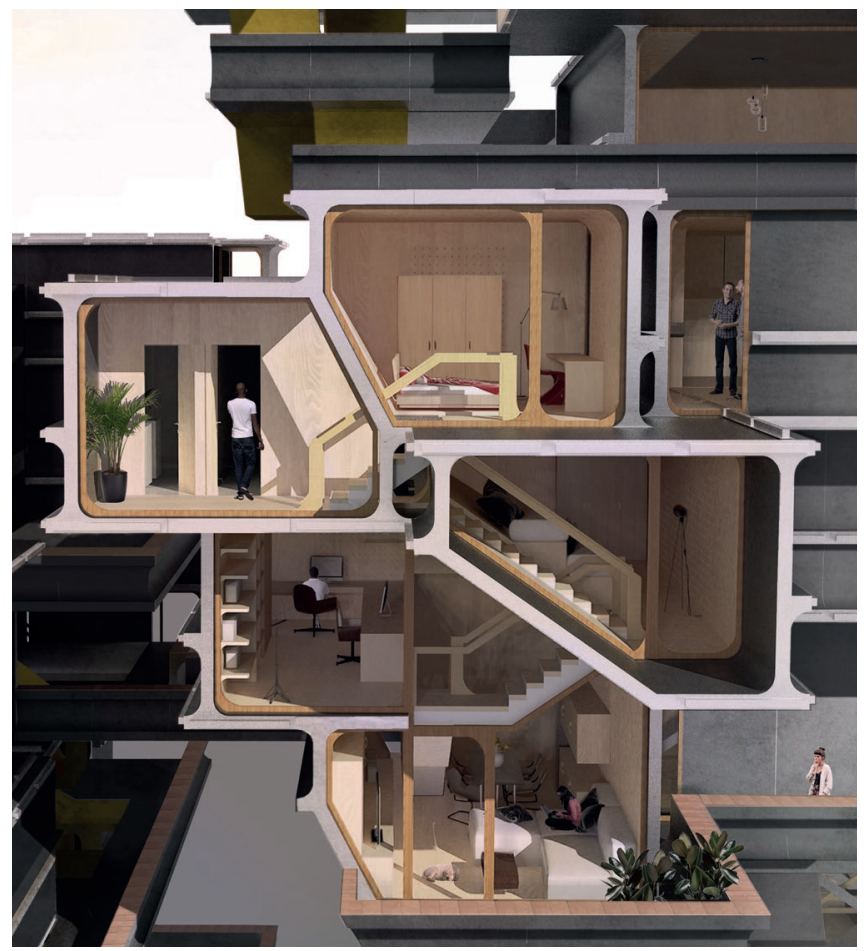

Figure 1. Julia Baltsavia, i-Architecture (2017). (C) Unit 19/DCL.

communities to be active co-producers of their virtual and physical environments? How can this affect historical and cultural understandings of the meaning and value that the digital holds for architecture's future? The paper speculate on answers to these questions by first presenting aspects of a beta-theoretical framework that promotes a possible answer to the consequences 'becoming digital' has had in the architectural discipline through the concept of the 'discrete'. Towards the end of the paper the discrete will be briefly demonstrated through projects developed over the last several years with students from Design Computation Lab (DCL) directed by Mollie Claypool, Manuel Jimenez Garcia, Gilles Retsin and Vicente Soler, located at The Bartlett School of Architecture, UCL.

\section{BECOMING DIGITAL}

To begin to provide a possible series of provocations for the future of a discipline that can respond to the above questions, it is necessary to do a complete rethinking of the way in which we utilise digital tools and technologies, as well as the processes and production chains of neoliberal capitalism to reinvigorate and release our discipline - and society - from the limitations and constraints of our digital contemporaneity. These two things - the microcosm that design can often take form in, and the macrocosm of culture and environment in which it becomes physically realised in - should not be separated. Therefore designing with advanced digital tools and techniques, but then utilising manufacturing, fabrication and assembly practices that are extremely wasteful and inefficient in terms of impact on the environment, time and resources, makes little sense. As a possible way out of this status quo this paper will propose the notion of architecture as not just becoming digital, but becoming 'all-digital,' or 'discrete,' in both process (design and production) and in the very nature of the artefact or architectural object itself.

An 'all-digital' or 'discrete' approach has roots in 20th century architecture particularly in the work of Jean Prouvé (Maison Tropicale 1949-1952), Buckminster Fuller (exemplified by his work Nine Chains to the Moon, 1938), Frei Otto (notably the Munich Olympic Stadium, 1972) who developed entire production chains for their work (amongst others surely also recognised elsewhere in this issue of AD). However, these architects were still limited by the modernist paradigm for architectural syntax, i.e. column, beam, floor slab, stair, et cetera (although Fuller made some progress in disrupting this with the Dymaxion House (1930), as did Otto). When we move away from building elements being specific to their architectural function and towards an architecture made of a discrete set of parts then we begin move into the wholly digital paradigm, thinking of building blocks as open-ended, scalable, universal and versatile.

This argument is further contextualised within/against current discourse on the discrete from the work of Daniel Kohler and his 'mereological' quantification of urbanism ${ }^{2}$ to Jose Sanchez's project to connect the discrete to participatory systems and the establishment of a new architectural commons. ${ }^{3}$ Philippe Morel's previous work with the Computational Chair (2004) explored the potential of voxel-based systems in relationship to automated manufacturing such as CNC-milling. This author's co-directors, Gilles Retsin and Manuel Jimenez Garcia, are also prominent voices exploring the potential of these ideas. Furthermore, contemporary projects such as WikiHouse (2011-) or the work by ENSAMBLE Studio such as Cyclopean House (2014-2016) are attempts to pursue aspects of a all-digital, discrete project. However while WikiHouse is still a highly be- spoke and customised model for the production of housing and thus exists still within earlier digital paradigms. The Cyclopean House takes on board distributed manufacturing and developed a discrete kit of parts yet the resultant architecture has a high degree of fixity.

\section{FULL AUTOMATION IS COMING}

Automation here provides an important context in which to situate the future of the digital. The construction industry is one of the least digitised industries in the world. ${ }^{4}$ Yet the move towards the full automation of labour in architectural design and construction is a reality which the disciplines of the built environment must confront. While this is already happening in different venues throughout the disciplines of the built environment - from software development to traditional manual labour professions - the way they approach the digital is often isolated within the specificity of various specialisations or is task-orientated. To propose the possibility of full automation, we will draw two parallels or relationships 


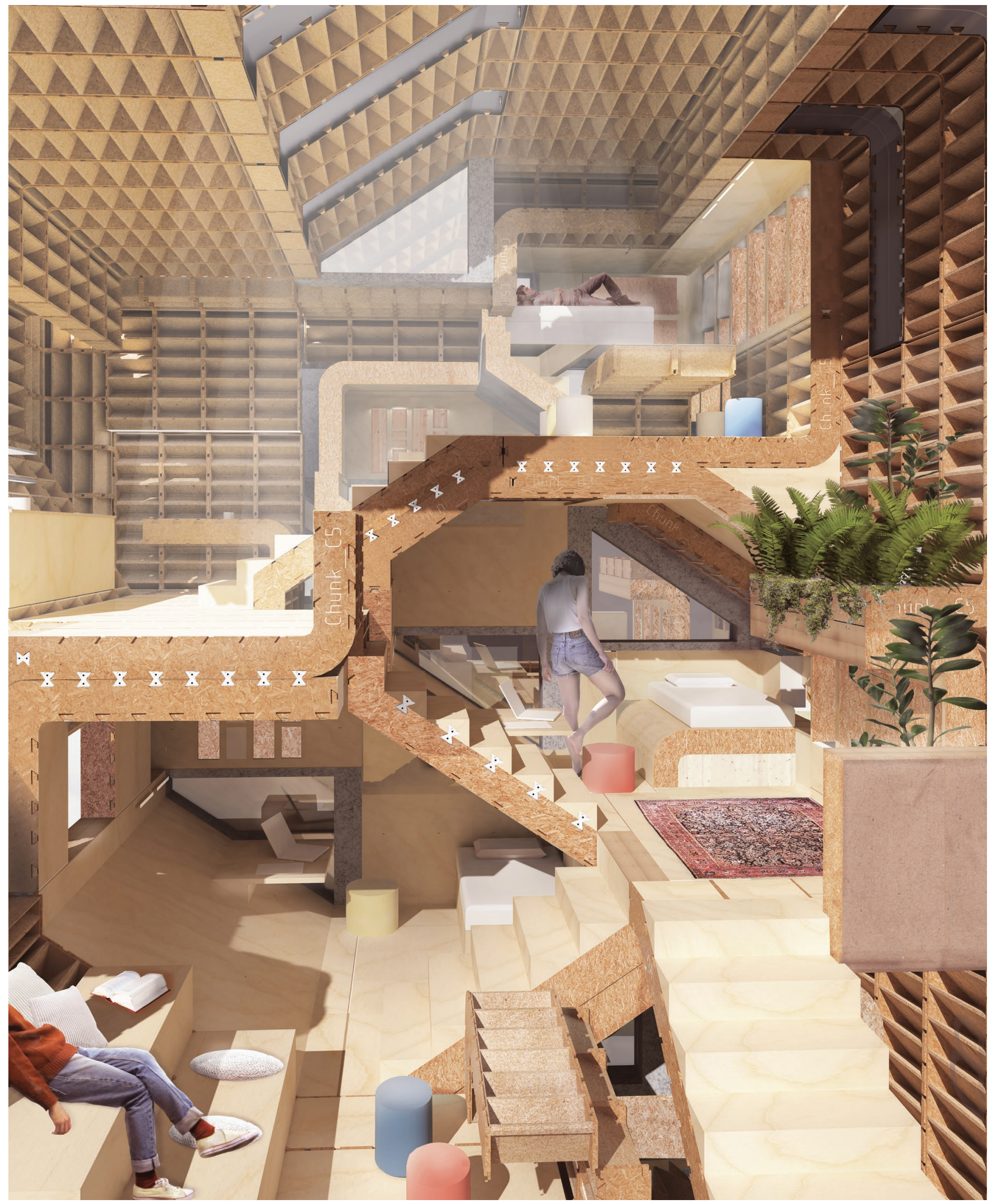

Figure 2. Alessandro Conning-Rowland, Chamfer (2018). (C) Unit 19/DCL. 


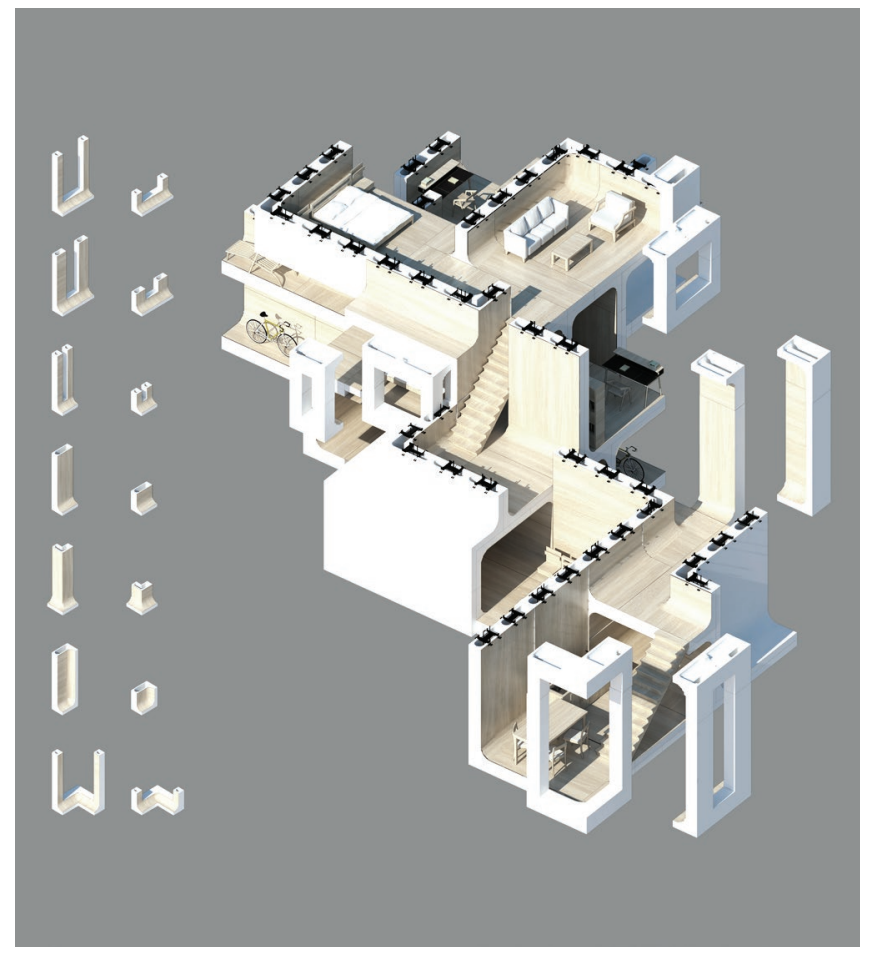

Figure 3. Ossama Elkholy, Cooperative Casting (2018). (c) Unit 19/DCL.

that can act as contexts for the work that I will present. The first is that we must draw a line between the terms digital (or the 'virtual') and full automation (or the 'physical'), as the essence of being 'all-digital' is to consider that both the virtual and physical occupy the same space - that of the 'real', or Real. On a macro scale, however there is a lack of an overarching syntax between disciplines. Although the adoption of BIM softwares such as Revit have succeeded in bringing different built environment specialists together into one software package under the guise of ease of communication across disciplines, buildings have become ever-more complicated (and costly) in the ways in which they are put together.

This leads us towards a complete rethinking of the basic building blocks of architecture, and is the catalyst for the second parallel: from the digital to the discrete. ${ }^{5}$ This will be expanded upon further in the next section of the paper. What is important to note is that the kind of approach towards the discrete in this work (as does the work of others working within the discrete such as Jose Sanchez) draws from the writings of contemporary philosopher and theorists who promote full automation, notably technological left-accelerationism such as the work of Nick Scrnicek, Alex Williams, Benjamin Bratton and the collective Laboria Cuboniks. Contextualising the work alongside manifestos such as Laboria Cuboniks "Xenofeminism: A Politics for Alienation" (2015), DCL believes in the need to "strategically deploy existing technologies to re- engineer the world." This is not an impossible challenge, nor is it "a free-floating project, since [the] frameworks [...] already exist and have traction in the world." It requires an assessment of, engagement with, and disruption of, the economic, social and political issues that currently restrain societal shifts towards the all-digital, the discrete and full automation, whether these are political, economic or cultural, or are stereotypes or discriminatory practices.

As Srnicek explains further in Platform Capitalism (2016), "in order to understand our contemporary situation, it is necessary to see how it links with what preceded it. Phenomena that appear to be radical novelties may, in historical light, reveal themselves to be simple continuities." ${ }^{\prime 8} \mathrm{~A}$ new generation of designers are now questioning the lack of social value and impact of the work of previous generations of the digital whose work ultimately was unable to translate into architecture which holds real positive value for, and of, the wider public. That work, using Srnicek's terms, are therefore 'simple continuities.'

\section{QUALITIES OF THE DISCRETE}

Architecture is a profoundly material discipline that must acknowledge who it is supposed to serve in more meaningful and valuable ways. To work with an all-digital, discrete framework is therefore to be against neoliberalism, monopolisation, centralisation, customisation, localism, consumerism, the analogue, non-scalablity, and highly discrete and laborious design production (some being qualities of what Scrnicek and Williams refer to as "folk politics"). ${ }^{9}$ By promoting systemic thinking, universal and flexible frameworks, economies of scale, platforms, open-source, decentralisation, the prototypical, mobility, prosumerism, the digital, scalability, and continuity in design production, we can propose the all-digital as an alternative future to the status quo.

An all-digital, discrete framework is aligned with the argument towards the discretization of the spline that the architectural historian Mario Carpo argued for in his groundbreaking essay "Breaking the Curve" in Art Forum in 2014. ${ }^{10}$ Drawing from work on digital materials by Nick Gershenfeld at MIT Centre for Bits and Atoms allows use to rethink the basic building blocks of architecture as discrete data. Gershenfeld and his collaborators defined a digital material as being "assembled from a discrete set of parts, reversibly joined in a discrete set of relative positions and orientations" and has the same structure as data in a computer programme. Digital materials by their very nature are able to transcend scales and platforms due to their (geometric, structural, material) abstraction as they can be compared to the children's game Lego: every piece has a male-female connection which is the equivalent of the 0 and 1 in digital data. ${ }^{11}$ Architecturally, the design possibilities - or the way how parts can combine and aggregate - can be defined by the geometry and therefore, design agency, of the piece itself. Utilising discrete, digital materials therefore can be more inclusive and equitable as a framework for design. For the work of DCL this enables a syntax of digitisation that connects together the parallels mentioned earlier: from the digital to the all-digital discrete, 


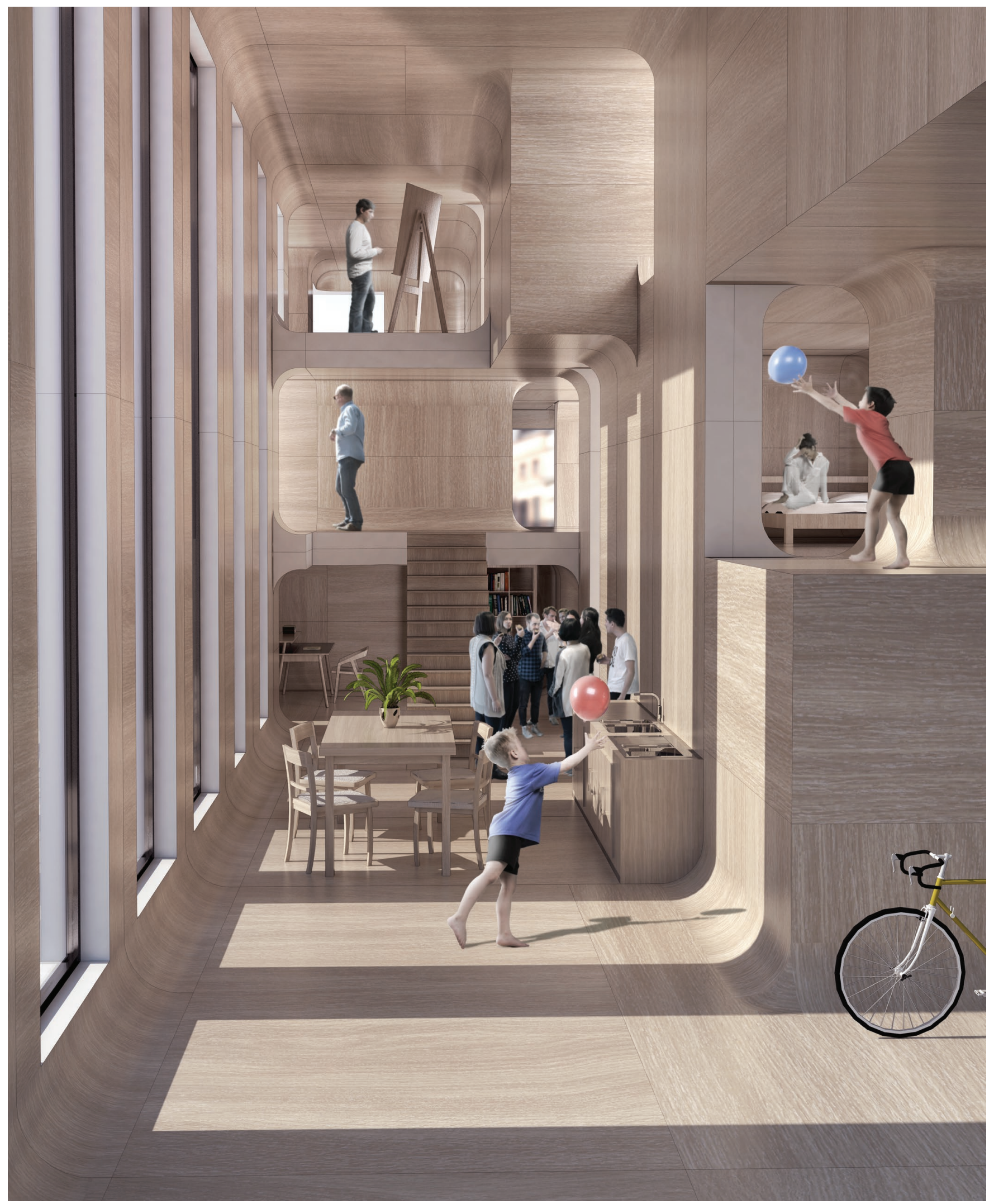

Figure 4. Ossama Elkholy, Cooperative Casting (2018). C Unit 19/DCL. 


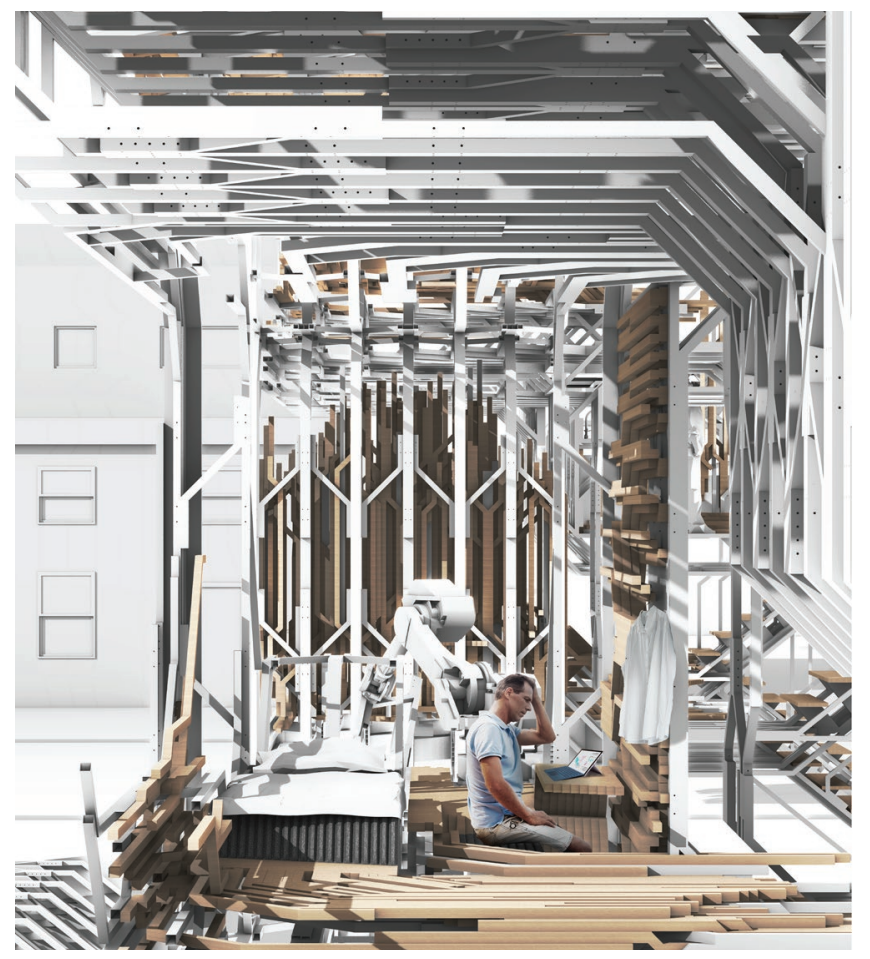

Figure 5. Shogo Suzuki, Digital Metabolism (2018). (C) Unit 19/DCL.

and from virtual to physical.

\section{PROSUMERISM AND CO-PRODUCTION}

Now it is possible at this point in the paper to begin to contextualise an all-digital discrete approach amongst current economic and social paradigms. The work of DCL is in direct contrast to today's smart gadgets and devices that emphasise individualised and real-time fully customisable experience of the built environment. This paradigm of the individual is ignorant of the meaning and value that that individual could add to the process of producing their physical environment: it is merely the customisation of a standard. The 'end-user' has a limited amount of perceived value in this kind of economic model.

The work of DCL is against privileging the notion of the 'enduser' as well as customisation for the sake of a 'personalised' architecture, and is for the integration and co-production of the 'user' alongside the designer and other parties at all stages of design, fabrication, assembly and inhabitation of architecture. Our projects recognise that the way in which many digital technologies have been used succumb to the constraints and protocols determined by systems of power and centralised networks of capital and capitalist production. By advocating a participatory, co-produced framework for architectural production that is all-digital and discrete, the concept of 'prosumption' (or the 'prosumer'), rather than consumption (and the consumer) can be engaged with. This enables prosumer(s) - embedded at each stage of the design, fabrication and assembly process, and over the course of the period of ownership of the house - to increase the value of their own impact into the architectural system by embedding their knowledge into our systems of production. The work of Ivo Tedbury (2017) (figures 1, 2, and 5) notably his project Semblr explored developing open-source softwares such as web or desktop-based apps enable non-specialised users (the 'layman') to access design tools in order to use them to specify their needs and test out different outcomes, using economic, physical (eg. site-based) and/or social constraints to do so. Users can specify how many parts they need according to their current needs, taking into account any possible predictions for required adaptations over time to changing financial or social circumstances. In Tedbury's project, this was explored first through the deployment of a home for a single-person, which was then expanded to a family home.

\section{AUTOMATED REDISTRIBUTION}

An all-digital discrete approach is as it is fully automated, these technologies can also aid in the predicting of how the system may cope with or anticipate changes in the future as well as reducing the amount of human labour (and therefore a degree of overall cost of design and construction).

Engagement with Jeremy Rifkin's concept of 'zero marginal cost society ${ }^{\prime 2}$ allows for us to propose autonomous robots that can be used to assemble, disassemble and reassemble entire buildings, each picking up a parts and distributing them where required, notably in Tedbury's project mentioned above. These techniques require substantially less human labour (almost zero) typical of traditional construction or assembly of housing, enabling a redistribution of resources across society. In this approach, becoming all-digital utilising full automation has the potential for much larger impact on the way the production of the built environment is structured, opening up opportunities for rethinking relationships to both work and leisure, similar to the argument that Scrnicek and Williams put forward in Inventing the Future: Postcapitalism and a World Without Work (2015).

On a different scale, by designing into the framework a chance for wider community-led engagement with the geometric (structural, spatial, material), economic and social rules of the part- to-whole relationships that are built into all-digital discrete architectural elements, communities at whatever scale can inform the way the social, political or economic models of the whole (eg. the architectural outcomes) as the syntax between each scale remains the same. For example, more traditional construction materials such as pre-cast concrete can be utilised alongside all-digital discrete kits of vacuum-formed moulds that allow for relatively quick, repetitive fabrication of parts such as in Oscar Walheim's project Avila Automatic (2017). Lightweight materials such as foam (sprayed with fibre-reinforced concrete) as in Julia Baltsavia's project i-Architecture (2017) or OSB and cardboard as in Alessandro Conning-Rowland's project Chamfer (2018) (figure 3) can be used and designed to be fabricated for the least amount of waste possible and to forego the 


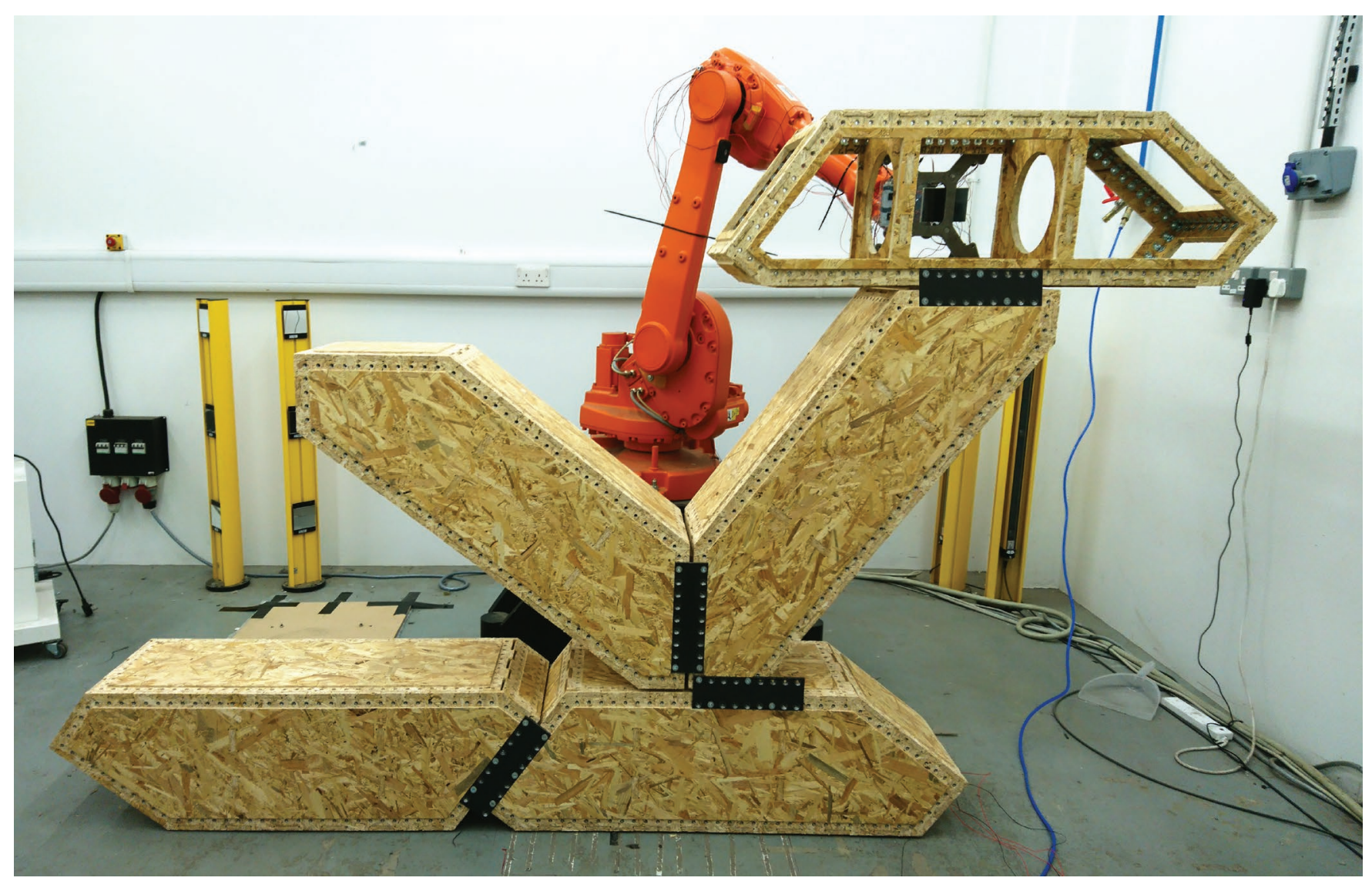

Figure 6. Ivo Tedbury, Semblr (2016), @ Ivo Tedbury/Unit 19/DCL.

use of heavy machinery in assembly. If parts individually act as one half of a mould for in situ concrete casting, a community can uses the set of EPS moulds to design and negotiate spatial configurations over time with varying degrees of privacy and temporality, making areas of the housing permanent by casting when required and negotiated by the community as in Ossama Elkholy's project Cooperative Casting (2018). Furthermore, if parts are distributed according to users needs in real-time by relative or even gantry-hung robots, as in Shogo Suzuki's project Digital Metabolism (2018), density and porosity can begin to syntactically link to the ways users use their homes, their moods and lifestyles, communicating on a neighbourhood or more local level.

The redistribution of resources enabled through a all-digital discrete model allows for increased inclusivity, distributing knowledge (both specialist and non-specialist) throughout the project, providing for more equitable and democratic production of architecture. The design question for architects therefore shifts from how buildings respond to a social or physical contexts through their appearance or presence, to how they are produced, and thus embody particular cultural conditions, including economic, political or social values. In this, the role of the architect shifts towards that of a designer of a system, where the architect manages a conceptual and methodological framework for architectural production. Importantly, it also enables users to not be passive receivers of knowledge via specialists, but active participants in informing how automated technologies are used and the shifts in conceptions of value and social practices that they might produce. Otherwise, what are we (you, architect) doing this for?

\section{AND NOW, FROM THE DIGITAL TO THE DISCRETE}

Advanced digital fabrication and manufacturing technologies such as industrial robots and 3D printers are commonly used in construction either as representative of human labor (replacing and mimicking actions of the human body) or on the other end of the spectrum, as representational devices: to make copies/replicas of existing building elements. Recent examples include SAM the robotic bricklayer by Construction Robotics and Winsun's 3D printed houses, or 3D printed wall panels. Buildings realised by the architects of the first digital turn were/are often hugely over- budget and inefficient as the basic building blocks for architecture are still planned and put together through processes that are still very much reliant on techniques developed in the 19th century with the advent of the Industrial Revolution; e.g. a very slow, laborious, and highly discrete production framework. In addition, the legal system has only now just begun to catch up with a system where parties are simultaneously an author and owner of a design. 


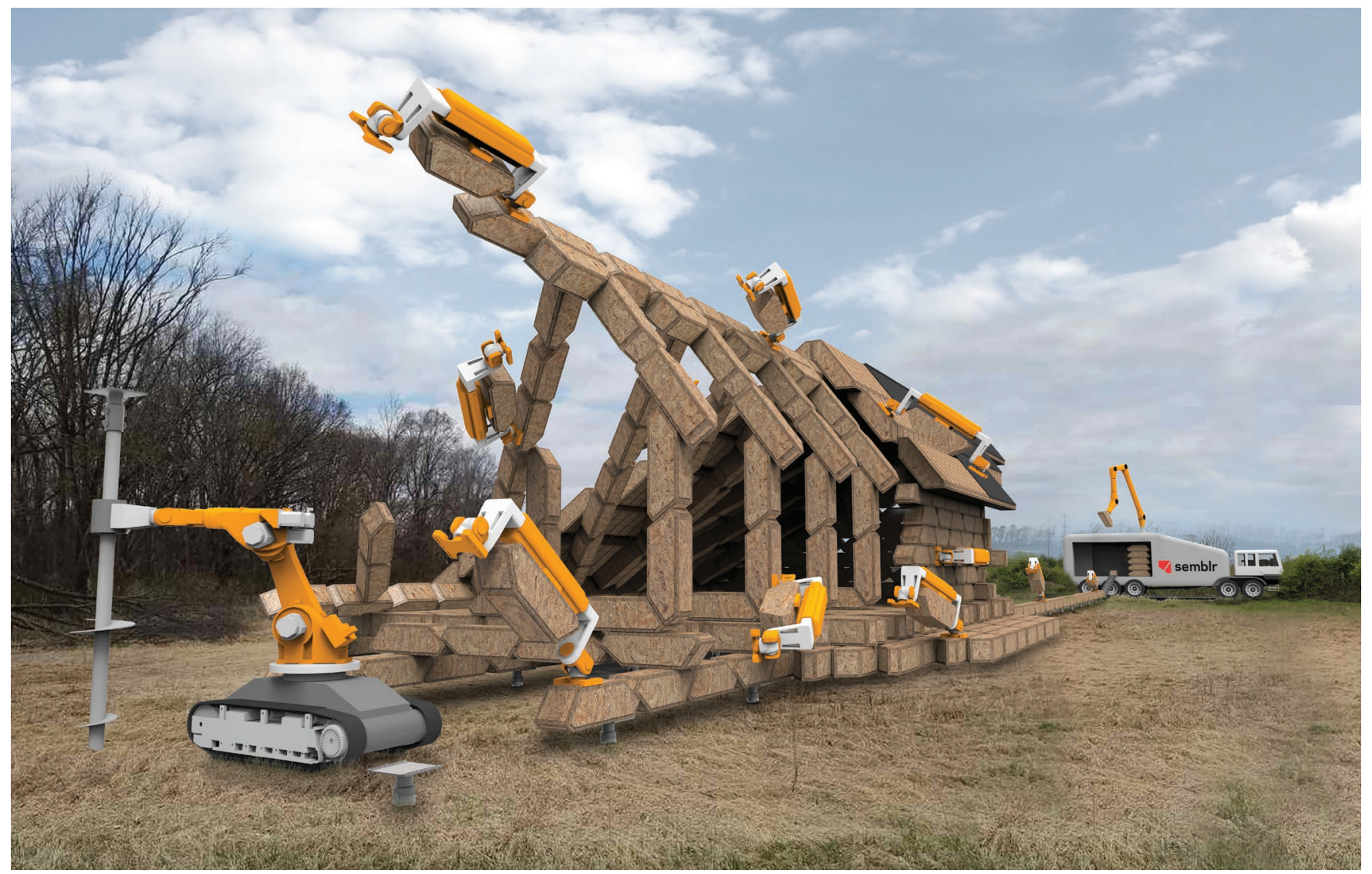

Figure 7. Ivo Tedbury, Semblr (2016), (C) Ivo Tedbury/Unit 19/DCL.

Utilising smart contracts and blockchain, we can speculate on a near-now in housing production that disrupts this dichotomy where design and construction are held in opposition (whether due to financial, political, legal or socio-cultural issues). Ownership can be incremental and capital transparent. Overly-specific building elements as in conventional design where every piece is designed and fabricated with high degrees of specificity and low tolerance have no place in this kind of model. Instead, through the discrete, building blocks are part of a feedback loop between design and fabrication. Building blocks can be distributed with an exactness to the virtual model, with high tolerances due to use of robotics to programme both fabrication and assembly behaviours. This is closely aligned to Gershenfeld's recognition that while fabrication technologies are embedded with digital logics, materials were analogue. In a all-digital discrete model for architecture, there is almost no difference in architectural syntax between design, fabrication or assembly. Furthermore, this kind of platform can be coordinated to cross-scale in terms of systems of material to labour, from material manufacturing to post-occupation and from analogue labour to automated labour. The model of all-digital discrete facilitates our inevitable future of complete digitalisation and full automation.

\section{ENDNOTES}

1 Bill Gates, talk given at COMDEX, 1997.

2 Daniel Köhler, "Large City Architecture: The Mereological Mode of the Quantified City," International Journal of Parallel, Emergent and Distributed Systems 32 (2017).

3 Jose Sanchez, "Combinatorial Commons: Social Remixing in a Sharing Economy," Architectural Design 87, no. 4 (2017): 19.

4 McKinsey Global Institute, "Reinventing Construction: A Route to Higher Productivity" (New York: McKinsey \& Company, February 2017).

5 The discrete is the subject of a forthcoming AD to which this author has contributed, edited by DCL co-director Gilles Retsin. This signifies that the discrete has now entered public consciousness within the discipline as one way in which the digital is being reevaluated.

6 Laboria Cuboniks, "Xenofeminism," Laboria Cuboniks official website, accessed January 30, 2019. http://www.laboriacuboniks.net/\#zero/3.

7 Nick Srnicek and Alex Williams, Inventing the Future: Postcapitalism and a World Without Work (London: Verso, 2015).

8 Nick Srnicek, Platform Capitalism (London: Polity Press, 2016).

9 Nick Srnicek and Alex Williams, Inventing the Future.

10 Mario Carpo, "Breaking the Curve: Big Data and Design," Art Forum (February 2014).

11 Neil Gershenfeld, et al., "Macrofabrication with Digital Materials: Robotic Assembly," Architectural Design 85, no. 5 (John Wiley \& Sons, 2015): 123.

12 Jeremy Rifkin, The Zero Marginal Cost Society (Spokane Valley, WA: Griffin, 2014). 